\title{
VARGAS VILA, INTELECTUAL
}

\author{
POR \\ Juan CARlos González Espitia \\ University of North Carolina at Chapel Hill
}

A la memoria de Rafael Gutiérrez Girardot, intelectual y maestro

En abril de 1998, al final de una conferencia en la Feria Internacional de Libro de Bogotá a la que yo asistí, y en la que el profesor Rafael Gutiérrez Girardot presentaba su libro Jorge Luis Borges: El gusto de ser modesto, alguien le pidió que diera nombres de individuos colombianos a quienes él considerara dignos de ser llamados intelectuales. En realidad, la pregunta era más directa y alevosa -el que preguntaba dijo algo así como "entonces para usted, ¿es que hay intelectuales en Colombia?"-. Era claro que la pregunta, con galicismo y todo, buscaba picar la lengua del conferencista, hacerle soltar alguna diatriba contra las miserias del provincialismo colombiano sobre las que ya había escrito de una y otra manera. Gutiérrez Girardot se caracterizaba por no tener pelos en la lengua ni en la pluma, por tensar el arco y echar flechas devastadoras e inapelables, tan refinadas y certeras que alguno llegó a llamarlo "francotirador", aunque él no fuera de los que tirara la flecha y escondiera la mano. Gutiérrez Girardot decía lo que pensaba, pero también pensaba antes de decir, así que no era tan fácil picarle la lengua y esta vez no fue la excepción. Vino una larga pausa y la única respuesta que Gutiérrez Girardot dio, sin diatriba ni nada, fue "Vargas Vila, tal vez". Sin más, pasó a la siguiente pregunta.

En las páginas que siguen exploro la respuesta, que en realidad es una pregunta, formulada por Gutiérrez Girardot el siglo pasado. El objetivo es examinar la idea general de quién es o qué es el intelectual, la idea específica del intelectual hispanoamericano, y la idea particular que ayude a responder a la pregunta sobre Vargas Vila como intelectual colombiano emblemático. Dicho en otras palabras, el propósito es resolver la opacidad del "tal vez" con que Gutiérrez Girardot calificó el papel como intelectual de Vargas Vila y tratar de dejar sentadas las bases de una discusión proyectiva y provechosa sobre la figura del escritor bogotano.

La introducción misma del término "intelectual" en el lenguaje común ofrece pautas significativas y muestra su relación directa con el contexto histórico durante el que Vargas 
Vila desarrolló su carrera como escritor. El 13 de enero de 1898 el reconocido escritor Èmile Zola publicó en el periódico L'Aurore una carta abierta, titulada "J'Accuse", en la que incriminaba al gobierno liderado por Félix Faure de encarcelar injustamente al capitán Alfred Dreyfus por traición, supuestamente porque había vendido secretos sobre armamento francés a los alemanes. Zola alegaba que los militares habían aportado evidencia falsa contra Dreyfus, quien era judío, y que las instituciones habían aceptado condenarlo injustamente como chivo expiatorio. El elemento más radical de la carta de Zola fue que acusó a los oficiales y al sistema judicial de antisemitismo. Un día después de la aparición de J'Accuse, el director de L'Aurore, Georges Clemenceau, publicó un documento firmado por escritores, profesores y artistas en el que apoyaban abiertamente a Zola. El título dado por Clemenceau al documento fue "Manifeste des intellectuels" ("Manifiesto de los intelectuales" [Johnston 43]). La palabra intelectual, que hasta entonces había sido utilizada sólo esporádicamente y por lo general con una connotación negativa en la que se señalaba a alguien como diletante y pretencioso, empezó a popularizarse. La apropiación del término en sentido positivo y con fines críticos por parte de Clemenceau produjo la respuesta inmediata de voceros conservadores del "orden social" como Maurice Barrès. Ellos cuestionaban y hacían burla de un grupo de individuos que se presentaban públicamente con la tarea de reprobar los asuntos públicos para decidir qué era justo o injusto sin tener el conocimiento o capacidad profesional para hacerlo (Szacki 231). Para empezar, entonces, desde la aparición del término, el intelectual se ve a sí mismo como alguien con la capacidad para ofrecer lineamientos y críticas en momentos que considera cruciales para su sociedad. En este mismo sentido, el término, que inicia su carrera como autodefinición y como toma de posición, no admite la posibilidad de ser entendido como una mención de honor o de reconocimiento. Estas características son fundamentales para entender a Vargas Vila como intelectual hispanoamericano.

La idea del intelectual surge en relación con una lucha de corte liberal, inclinada a defender valores derivados de la Revolución Francesa -el derecho a la diferencia, la convicción en la noción de igualdad, o la confianza en la idea de que el conocimiento libera al ser humano- que ponen en evidencia el entronque existente con el ideario romántico. Basta con recordar la fórmula acuñada por Víctor Hugo sobre el romanticismo como liberalismo en literatura y el hecho que el manifiesto de 1898 fuera liderado especialmente por escritores para constatar que el intelectual surge como figura pública que se encuentra directamente relacionada con la literatura y al mismo tiempo profundamente interesada en los cambios políticos. Zola y Víctor Hugo, que son precisamente ejemplos de la conjunción entre quehacer literario y convencimiento político, sirvieron como hitos y modelos fundamentales para la generación de jóvenes a la que pertenecieron Vargas Vila, Rubén Darío o José Enrique Rodó.

Esta concomitancia es esencial para iniciar una definición en el caso hispanoamericano decimonónico pues, muy al contrario de lo que se piensa generalmente, la idea

Revista Iberoamericana, Vol. LXXXI, Núm. 252, Julio-Septiembre 2015, 805-826 ISSN 0034-9631 (Impreso)

ISSN 2154-4794 (Electrónico) 
del intelectual no está relacionada necesariamente con la del erudito o letrado. En Hispanoamérica buena parte de la interpretación de lo que significa ser intelectual está enmarcada dentro de una tradición muy rancia que pone en un mismo cajón sapiencia y literatura. Tal tendencia abona el camino para una falsa consideración propia del ámbito hispanoamericano: aquella que considera intelectualidad como sinónimo de "buena literatura" y que produce muchas confusiones pues se considera erradamente que todo intelectual es un gran literato, que todo literato es intelectual, que un regular escritor no puede ser intelectual, o que un no literato no pueda ser intelectual. Semejante problema de interpretación se hace más profundo dentro de las particularidades del siglo XIX, cuando el sistema social hacía parecer como verdad inapelable esa tautología inexistente. Sin embargo, valga decir que de todas maneras durante el XIX la categoría de intelectual define por lo general a aquel que también es escritor de literatura.

En el sentido derivado del origen de la idea en 1898, el intelectual se caracteriza necesariamente por su inclinación a intervenir en los asuntos públicos de su momento, es decir por su interés en el ejercicio político. Esta característica de la definición resulta en corolarios que controvierten drásticamente la preconcepción sobre quién es intelectual en Colombia. Por ejemplo, y sólo para hablar de la segunda mitad del siglo XIX colombiano, Rufino José Cuervo, Baldomero Sanín Cano, José Asunción Silva y aún Miguel Antonio Caro en Bogotá, Joaquín F. Vélez en la costa, o Tomás Carrasquilla en Antioquia, quedarían restringidos al grupo de los eruditos. Por otro lado en el grupo de los intelectuales se incluiría contradictoriamente a Julio Arboleda, Rafael Núñez -el archienemigo de Vargas Vila-, Manuel Murillo Toro o Juan de Dios “El Indio” Uribe. Sin embargo, no es el interés aquí expurgar individualidades mediante el uso de un rasero excluyente. La idea de establecer una diferencia entre el erudito y el intelectual puede ser controvertida toda vez que el sólo hecho de poner en el ruedo público una idea propia o una opinión - un poema, un cuento, un ensayo, una novela, una obra teatral-cualifica la acción como una acción política. El propósito de esta distinción es tener en cuenta la fluidez e inestabilidad de la función del intelectual. ${ }^{1}$ Hay intelectuales con mayor interés

\footnotetext{
La definición del intelectual en términos de la disyuntiva entre búsqueda individual de conocimiento y compromiso público sigue siendo tema de debate. El desplazamiento hacia la cultura de la ultraespecialización y la indudable conexión entre los poseedores de conocimiento y las instituciones de educación superior hace aún más borrosa una posible definición. Es por esta razón que las últimas discusiones sobre el tema indican un retorno a la definición del intelectual decimonónico descrita anteriormente, claramente relacionada con la búsqueda de cambio político hecha por individuos reconocidos por su competencia en un campo específico de conocimiento. Jerzy Szacki ofrece un buen resumen del estado actual de la definición: "La palabra 'intelectual' no se aplica habitualmente a toda la gente haciendo trabajo intelectual o a aquellos que obtienen un alto nivel de destreza intelectual, sino solamente a cierto segmento de ese grupo, específicamente aquellos que han decidido salir de sus 'laboratorios o bibliotecas' hacia el mercado político, hacia el foro de la vida pública. El intelectual entendido así siempre aparece en un doble rol social: el rol del especialista en uno u otro campo de trabajo intelectual (escritor, científico, profesor, filólogo) y el rol de alguien que por alguna razón siente
}

Revista Iberoamericana, Vol. LXXXI, Núm. 252, Julio-Septiembre 2015, 805-826 ISSN 0034-9631 (Impreso)

ISSN 2154-4794 (Electrónico) 
e influencia en el ámbito público que otros, pero la búsqueda de ascendiente político es un factor insoslayable del intelectual hispanoamericano decimonónico.

La producción de Vargas Vila no se separa del denominador común de otros pensadores hispanoamericanos en su cualidad literaria. ${ }^{2}$ Igual que sus contemporáneos, Vargas Vila articula la realidad y la identidad de América en términos estéticos. Aún en los muchos momentos en que describe el entorno hispanoamericano con detalles repulsivos o grotescos, la descripción se mantiene dentro de una normatividad mediada por lo estético, esto es, por lo bello, así sea a contrario. En ocasiones la descripción chocante, el abrir de puertas de cuartos lóbregos en extremo, se convierte en Vargas Vila en el deseo de mostrar una puerta de salida diferente a la de los proyectos que estuvieron en boga desde finales del siglo XVIII para esta región. Se debe entender a Vargas Vila como intelectual cuya función fue incomodar tanto a la comunidad a la que se dirigía (desde el exilio) como a la comunidad en la que residía (como exiliado). Esta fue, por supuesto, una estrategia discursiva por parte de Vargas Vila, pues en realidad tuvo una vida disciplinada y hasta aburrida, alejado del ruido y de las reuniones sociales y sólo volvía a la vida pública para alimentar la leyenda de su excentricidad.

El intelectual tiende a tener un papel local y en ese sentido obedece a necesidades temporales, ataca directamente idiosincrasias a la vez que se vincula con ellas, y su lenguaje registra constantemente los cambios en la discusión y se adapta a ellos -aunque esa adaptación esté regida por un único precepto que nunca parece fluir: la oposición. Estas características del intelectual, cuya validez es aplicable al intelectual decimonónico, son relevantes en el caso de los países hispanoamericanos pocos años después de los procesos emancipatorios y en medio de búsquedas accidentadas sobre su propia identidad como comunidades. Entonces y hoy, el papel y condición del intelectual están determinados por la manera en que se relaciona con su medio. A lo anterior se añade que el poder de influencia del intelectual tiene relación directa con su prestigio entre el público. Esta influencia y este prestigio personales, traducidos en respetabilidad, irradian sus cualidades sobre la esfera de valores que el intelectual defiende (Molnar 9). Sin embargo, términos

el llamado a la participación activa, y aún al liderazgo, en alguna comunidad supra-profesional"; en "Intellectuals" (231, énfasis en el original).

Edward Said, a cuyas ideas sobre el intelectual voy a referirme luego con mayor detalle, presenta con claridad la relación existente entre escritura e intelectualidad: "Cada intelectual cuyo oficio es articular y representar perspectivas, ideas e ideologías específicas aspira lógicamente a hacerlas funcionar en la sociedad. El intelectual que dice escribir sólo para sí mismo o para sí misma, o con el único fin de aprender, o de hacer ciencia exacta, no es creíble, y no debe creérsele. Como el gran escritor del siglo XX Jean Genet dijo una vez, en el momento mismo en que alguien publica ensayos en el contexto de una sociedad ha entrado en la vida política; así que si no se quiere ser político entonces no se deben escribir ensayos o manifestar opiniones" (Representations 82, énfasis en el original. Todas las traducciones son mías).

2 Ejemplos canónicos aparte de los ya mencionados Darío, Rodó y Martí son Juan Montalvo, Eugenio María de Hostos y Rufino Blanco Fombona.

Revista Iberoamericana, Vol. LXXXI, Núm. 252, Julio-Septiembre 2015, 805-826 ISSN 0034-9631 (Impreso)

ISSN 2154-4794 (Electrónico) 
como respetabilidad o prestigio no pueden entenderse necesariamente como sinónimos de aceptación pública generalizada y tienen que ver más bien con características como la visibilidad, la capacidad para ver situaciones desde otro punto de vista, y especialmente la facultad de incomodar.

Otra característica derivada del noventaiocho es que el intelectual toma posición, defiende una idea o una causa teniendo como medida su propio convencimiento y el conjunto de preceptos -en principio liberales-sobre los que reposa su doctrina. Este rasgo marca una diferencia profunda con algunas definiciones más recientes que buscan adjudicar rasgos objetivos a la labor del intelectual. Un ejemplo de esa ansiedad objetiva es la definición ofrecida por Alan Montefiore, para quien el intelectual es "cualquier persona que tiene un interés comprometido en la validez y verdad de ideas en sí mismas, por ejemplo, por razón de su verdad y validez, antes que en sus relaciones causales con cualquier otro fin" (201). Nada más alejado de esta definición es lo que encontramos en la actitud de los intelectuales que firmaron el manifiesto de 1898 o de un intelectual hispanoamericano decimonónico como Vargas Vila. El interés de esos participantes en la discusión de su momento era político, y por tanto subjetivo y aún provisional. El intelectual no está comprometido con la Verdad sino con una posición que considera válida-verdad y validez son dos cosas bien diferentes-, y consecuentemente su función era, y es, la de señalar la invalidez de la posición del statu quo.

Entonces, una función del intelectual decimonónico, y de manera derivada del intelectual contemporáneo, es producir incomodidad, es estar constantemente incómodo con la situación, y poner al público con el que se relaciona en una constante situación de incomodidad. No extraña que aquellos más directamente afectados, aquellos más incomodados por la incomodidad del intelectual, lo consideren entrometido, impertinente o dañino. La impertinencia es una característica que Jean-Paul Sartre puso al centro de su definición del intelectual en Plaidoyer pour les intellectuels (1972) al afirmar que "es un hecho que un intelectual es alguien que no evita meterse en lo que no le importa" (12). Si en algo coinciden tanto los detractores furibundos de Vargas Vila como sus furibundos defensores es que él se ha erigido dentro de la cultura colombiana e hispanoamericana como una presencia incómoda, impertinente. No hay nada en la imagen de Vargas Vila que haga que el público vea en él una figura paternal, amistosa o mullida. Lo que Vargas Vila produce en el público es la idea de una rispidez fraternal, de un pasarse de la raya que hace que el lector se divida en sus adentros entre el escándalo y el elogio.

Esta posición intersticial, fronteriza entre la aceptación y la expulsión, hecha pública a la vez para y en contra de la sociedad, se constituye en la columna vertebral de la exploración de las representaciones del intelectual elaborada por Edward Said en 1993 para la reconocida serie de Conferencias Reith y publicadas posteriormente con el título Representations of the Intellectual (Representaciones del intelectual). Said logra una reveladora aproximación de la función y las características del intelectual contemporáneo que interesantemente hace referencia constante a ejemplos, citas y

Revista Iberoamericana, Vol. LXXXI, Núm. 252, Julio-Septiembre 2015, 805-826 ISSN 0034-9631 (Impreso)

ISSN 2154-4794 (Electrónico) 
características de individuos del período de entresiglos XIX al XX, y confirma un retorno a las ideas iniciales en las que nació el concepto. Mi estrategia en lo que sigue es ofrecer un breve resumen de las opiniones de Said a fin de apuntalar el concepto general occidental del intelectual, y al mismo tiempo incorporar una discusión sobre el intelectual hispanoamericano de entresiglos. El objetivo de esta doble aproximación es identificar elementos que den luz sobre el papel de José María Vargas Vila como intelectual colombiano.

Para Said el intelectual es alguien que se encuentra por fuera del círculo social, alguien literal o figurativamente marginal o exiliado que emite su opinión en la calidad de aficionado -en contraste con la idea del profesional que deriva su sustento de las acciones que ejecuta, el aficionado ejecuta sus acciones por un interés personal del que no deriva sustento exclusivo-, alguien que elabora un lenguaje que le permite confrontar el statu quo y decir su verdad a quienes tienen el poder (Representations xiv). El intelectual busca destruir los estereotipos y los esencialismos (x) y sólo puede lograr esa tarea si consigue cierto nivel de independencia de las presiones que ejerce la nacionalidad, el lenguaje, la tradición, el contexto histórico, o las instituciones como la academia, la iglesia, o los grupos profesionales (xiv). A pesar de su papel opositor, lo que manifiesta el intelectual llama la atención de grandes sectores de su sociedad y se constituye en una molestia para aquellos cercanos al poder, para los que se autodenominan expertos, para los que "moldean" la opinión pública y le hacen pensar que todo está bien -que los pocos de la caterva que están en el poder saben lo que hacen y que no se les debe cuestionar. El intelectual rebate el nacionalismo patriótico y el pensamiento corporativo, e impugna que existan privilegios anejos a la clase, la raza o el género (xii).

Es claro que las cualidades descritas anteriormente no hacen que los intelectuales tengan buenos amigos en las altas esferas de la sociedad, o que les premien con honores oficiales. No sorprende que el intelectual se encuentre en una posición de soledad, en continua proscripción. Si bien la exclusión y la marginalidad significan no recibir los premios, becas, y reconocimientos tan deseados por algunos, eso no significa que el intelectual no llegue a disfrutar de ciertas gratificaciones y hasta privilegios derivados de la condición exílica y marginal (43). Vargas Vila no es una excepción en este sentido; su condición de proscrito, de exiliado que no midió palabras para criticar a su propio país hizo que sus libros fueran leídos con mayor avidez en países diferentes al suyo, hizo que países como Ecuador y Nicaragua le ofrecieran posiciones diplomáticas de las que derivó su sustento, o que varias casas editoriales le ofrecieran contratos bien pagos por sus manuscritos, o que le invitaran como conferencista reconocido por la palabra fuerte y ácida. No se puede negar tampoco la complacencia que Vargas Vila sentía desde el exilio al escuchar su nombre dicho en voz baja por quienes reconocían en él un fustigador de la Iglesia Católica, o dicho a gritos desde los púlpitos por sacerdotes enfurecidos por las representaciones espantables que el bogotano hacía de los pastores de la grey.

Revista Iberoamericana, Vol. LXXXI, Núm. 252, Julio-Septiembre 2015, 805-826 ISSN 0034-9631 (Impreso)

ISSN 2154-4794 (Electrónico) 
En la conferencia titulada "Intelectuales y exiliados: expatriados y marginales" Said afirma que el intelectual exiliado existe en un estado intermedio, incómodo con la situación nueva que confronta y aún no liberado de la situación que se ha visto obligado a abandonar; medio comprometido y medio desligado; en un nivel sentimental y nostálgico, en otro nivel repetidor de ideas ya pasadas de moda o un paria a escondidas. El exilio es una característica frecuente del intelectual hispanoamericano. Una gran proporción de los productores importantes de opinión durante la segunda mitad del siglo XIX y el período de entresiglos ejercieron su función desde el exilio o informados por la experiencia del exilio. Por ejemplo, la vida, la obra y la temprana proscripción de José Martí desde los diecisiete años hasta su muerte en 1895 lo constituyen en una imagen del intelectual finisecular por antonomasia y lo hacen afín a las experiencias de otros pensadores públicos del período como Juan Montalvo, exiliado intermitentemente a partir de 1869, cuando tenía treinta y siete años y hasta su muerte en París en 1889, y el mismo Vargas Vila, exiliado desde 1887 con veintisiete años y hasta 1933, cuando muere en Barcelona. La expatriación del intelectual finisecular hispanoamericano hace que su experiencia y su voz sean el resultado de una triangulación que lo hacen al mismo tiempo presente y ausente. Esta doble condición de pertenencia y expulsión hace que su pensamiento se dinamice y le sirva como plataforma, para ser escuchado y rechazado a un mismo tiempo, en el entorno extraño en el que se encuentra y en el entorno que se ha visto obligado a abandonar. El efecto de esta triangulación incita al statu quo a intentar reducir la efectividad del discurso del intelectual expatriado, alegando, por ejemplo, que no vive nuestra realidad, luego no la entiende, luego su opinión no vale.

La situación de mutabilidad e inestabilidad hace que de manera extraña el intelectual como exiliado tienda a sentirse "feliz" con la idea de la infelicidad. La constante falta de satisfacción, que se traduce en desazón aguafiestas, puede llegar a convertirse no sólo en el estilo de pensamiento y de escritura del intelectual, sino en el espacio en el que ha de habitar (Said, Representaciones 39). Esta posición avinagrada, esta incomodidad que incomoda, que se complace en la propia incomodidad, es una característica que marca el fondo del pensamiento y la forma de la escritura de Vargas Vila y que se desfoga estilísticamente en la discontinuidad y la fragmentación. La producción de Vargas Vila sólo se puede caracterizar como discontinua, como corpus, como fragmentaria en su estilo, y manifiesta sólo a través de un discurso excéntrico y fragmentado. ${ }^{3}$ La evaluación que hace Said de la difícil escritura del pensador Theodor W. Adorno adquiere resonancias inusitadas si uno remplaza el nombre del pensador alemán con el de Vargas Vila:

3 De esta característica ya he hablado antes pero haciendo una lectura del estilo decadente vargasviliano. Un estudio más extenso sobre el estilo fragmentado de Vargas Vila y su conexión con la idea de nación se puede encontrar en el tercer capítulo de mi On the Dark Side of the Archive. Nation and Literature in Spanish America at the Turn of the Century.

Revista Iberoamericana, Vol. LXXXI, Núm. 252, Julio-Septiembre 2015, 805-826 ISSN 0034-9631 (Impreso)

ISSN 2154-4794 (Electrónico) 
El núcleo de Adorno como representación del intelectual como exiliado permanente, eludiendo lo nuevo y lo viejo con igual destreza, es un estilo de escritura afectado y elaborado hasta el extremo. Ante todo es fragmentario, brusco, discontinuo; no tiene argumento u orden a seguir. Representa la conciencia del intelectual incapaz de encontrar reposo en ningún lugar, en guardia constante contra las comodidades del éxito. ... Mucho más tarde en su carrera Adorno dice que la esperanza del intelectual no es necesariamente tener un efecto en el mundo, sino que un día, en algún lugar, alguien va a leer lo que escribiera exactamente como lo escribió. $(42)^{4}$

Sin embargo, una segunda reflexión de lo propuesto por Said me convence que en el caso de Vargas Vila no hay esta esperanza que Said parece indicar para su modelo del intelectual. Me parece más bien que en el autor colombiano la lección, lo que se saca de leerle lejos de la cacofonía de sus críticos y fanáticos, tiene que ver con la frescura que ofrece su visión escéptica del futuro hispanoamericano. Lo que se dice de Vargas Vila como escritor de su país casi siempre tiene que ver con su supuesto pesimismo y con su iconoclastia, pero yo prefiero hablar de Vargas Vila como escéptico - esto es, como intelectual- impregnado de una esperanza retorcida que antes que insulto es lamento ante el paraíso perdido. El retorcimiento es su marca personal. El exilio y oposición a ultranza fueron entonces los puntales de su propia conformación al nivel escritural y como persona pública. Vargas Vila nunca negó las leyendas que se tejían en torno a su persona como una elección consciente que buscaba mantener su imagen pública. Sabía que gran parte de su éxito tanto comercial como ideológico reposaba en la capacidad para mantener la atención. Este cultivo de la imagen pública es propio del intelectual que busca constituirse en foco que irradia un tipo de opinión que produce cambios. Said afirma que el intelectual es alguien que representa visiblemente un punto de vista y alguien que hace representaciones bien cimentadas a su público a pesar de las barreras que se le presenten (10).

Said sostiene así mismo que los intelectuales son individuos que tienen vocación por el arte de representar. Logran reconocimiento público, pero ese reconocimiento significa un fuerte compromiso y la aceptación de las vulnerabilidades que le son anejas (10). El intelectual tiene que presentarse doblemente, esto es, debe representarse. En otras palabras, el involucramiento representacional es performativo y aún dramático, y se manifiesta a través de un estilo personal único. El intelectual no muestra la vida

4 Esta maravillosa descripción tiene la capacidad de servir como admonición - "admonición" era una palabra querida a Vargas Vila- a las nuevas generaciones de lectores colombianos para que establezcan un estudio juicioso de sus pensadores que evite las preconcepciones fáciles de generaciones pasadas. Hoy se hace evidente la necesidad de leer con distancia la evaluación que Vargas Vila hizo de su país. Es hoy cuando la esperanza del intelectual de la que habla Said puede hacerse realidad en la reevaluación de Vargas Vila, no para decir que tuvo razón en todo lo que dijo, sino para entender qué dijo, por qué lo dijo, y por qué lo que dijo produjo las reacciones que produjo.

Revista Iberoamericana, Vol. LXXXI, Núm. 252, Julio-Septiembre 2015, 805-826 ISSN 0034-9631 (Impreso) ISSN 2154-4794 (Electrónico) 
pública como números o datos en frío, sino mediante el uso de estrategias discursivas y representacionales asociadas con las de la literatura (11). La crítica somera tiende a ver el estilo personal de Vargas Vila como pose y megalomanía, y tienen razón. Pero la cosa va más allá. La megalomanía y la pose tienen el objetivo claro de mantener su nivel de representación: Vargas Vila quiere mostrarse al público como la encarnación de un ideario tan claramente definido y tan drástico que no tiene otra salida que la de llevar la contraria a todo y en todo.

Así que la diferencia impuesta y aceptada es la marca fundamental de los intelectuales expatriados. La actitud contradictoria en Vargas Vila es el resultado de su exilio y de haber nacido en un país que confrontaba las consecuencias de su pasado como colonia. Hablando de Stephen Dedalus, el protagonista de Retrato del artista adolescente de James Joyce, Said afirma que este joven provinciano es el producto de un ambiente colonial que se ve avocado a desarrollar una conciencia intelectual de resistencia antes de convertirse en artista (13). Esta es la misma constante de Vargas Vila como intelectual. Desde sus primeros escritos políticos y literarios publicados en el destierro hasta su muerte en Barcelona, Vargas Vila fue un provinciano en Europa, un exiliado con una visión clara de su región como producto del colonialismo español y amenazada por el colonialismo estadounidense. El reconocimiento de esa condición se tradujo, así fuera amargamente en su caso, en la oposición radical. ${ }^{5}$

La expresión de libertad radical pero amenazada es la puerta de entrada para una definición del intelectual cuyo público está inmerso en las consecuencias de una situación colonial. La libertad radical significa necesariamente para el intelectual la obligación de evitar acomodarse por completo a cualquier posición política, aún si esa posición política refleja los ideales por los que ha luchado. Dice Said que la lealtad a una ideología no puede llevar al intelectual a aletargar su sentido crítico, o diluir sus objetivos iniciales contentándose con victorias a medias (30). Es esta libertad radical la que buscó Vargas Vila en su vida pública; nunca aceptó ningún rótulo a menos que la etiqueta dijera "Vargas Vila" a secas. En vida le causó prurito que lo encasillaran, que lo pusieran como parte de un grupo, de un movimiento, de una cofradía. Por eso causa un poco de hilaridad que los críticos - que vivimos de poner etiquetas, como aquella de "intelectual” que se intenta aquí- tengamos tanto problema para adscribir a Vargas Vila. Lo llamamos modernista, vanguardista, anarquista, liberal radical, romántico, chabacano o masón sin que realmente fuera ninguno de esos rótulos. Él tenía razón al decir que no

\footnotetext{
5 Una parte de la novela de Joyce citada por Said abre la pregunta sobre si el colombiano habría leído Retrato del artista adolescente, publicada en 1916. La afinidad de Vargas Vila con lo que escribe Joyce del joven Dedalus es inusitada: "Voy a decirte lo que voy a hacer y lo que no voy a hacer. No voy a servirle a aquello en que ya no creo, llámese mi hogar, mi patria o mi iglesia: y voy a tratar de expresarme en un modo de vida o arte de manera tan libre y tan completa como pueda, empuñando para mi defensa las únicas armas que me permito usar-silencio, exilio, y sagacidad" (cit. en Said 13).
}

Revista Iberoamericana, Vol. LXXXI, Núm. 252, Julio-Septiembre 2015, 805-826 ISSN 0034-9631 (Impreso)

ISSN 2154-4794 (Electrónico) 
escribía en castellano, que escribía en "Vargas Vila", porque además de acoplarse muy bien a su presunción, era la única manera de preservar su posición crítica.

Said agrega que, además de su función concreta en el entorno del público al que pertenece, el intelectual tiene como obligación universalizar explícitamente la realidad que confronta y establecer conexiones con aquellos que se encuentran en condiciones semejantes (32). Aquí radica un aspecto primordial de Vargas Vila como intelectual; su deseo incesable de representación lo constituyó en una figura reconocible para toda Hispanoamérica, un hecho comprobable en la venta continua de sus obras más conocidas, por lo general en el mercado del libro usado, a lo largo y ancho del continente. Lo mismo que en el caso de José Martí o Juan Montalvo, la intención escritural de Vargas Vila es de universalidad. La temprana manifestación de un enemigo común encarnado por los Estados Unidos en textos como Ante los bárbaros (1900) indica esa fuerte intención de conglomerar las experiencias particulares de los países al sur del río Bravo para articular una experiencia de opresión común y de carácter distintamente latinoamericano. Belona dea urbis (1918), un texto representativo de la producción de Vargas Vila durante el período de la Primera Guerra Mundial, manifiesta nuevamente esa intención universalizadora, esta vez para señalar los efectos del ansia desaforada de poder de naciones con vocación imperialista sobre los pueblos cuyas instituciones públicas se encuentran en gestación o expuestas por razón de su inestabilidad interna, no sólo en el ámbito latinoamericano sino también entre países europeos.

A lo largo de esta discusión se ha mostrado a Vargas Vila como un productor de opinión radical que se acopla a la idea del intelectual contemporáneo tal y como es percibido por Said. En ese sentido, cabría una crítica entendible de que visto así, de manera extemporánea, se estudia a Vargas Vila como si fuera un intelectual noratlántico del fin del siglo XX. Estoy dispuesto a conceder parcialmente frente a la crítica, no sin antes aclarar que la posición de Said, un pensador nacido palestino en Jerusalén bajo el mandato británico y que escribía en inglés desde la academia anglosajona, es la de un pensador que conoce bien la situación de los países en situación colonial o poscolonial, alguien que en carne propia experimentó los sinsabores del exilio, y cuyo objetivo fundamental en las conferencias de Reith fue encontrar la universalidad del papel del intelectual. Sin embargo, a fin de seguir al pie de la letra el principio que salmodia que no hay crítica completa ni justa, si se usan exclusivamente herramientas teóricas contemporáneas y foráneas en la producción de productores de saber del siglo XIX, es necesario revisar algunas ideas con respecto al intelectual hispanoamericano durante el período contemporáneo a Vargas Vila.

Posiblemente una buena manera de hacer ese trabajo es abordar ejemplos de intelectuales representativos, ligarlos con Vargas Vila, y derivar de sus experiencias e imágenes algunos rasgos comunes relevantes. Como escritores y como productores radicales de opinión, José Martí, Juan Montalvo o José María Vargas Vila se encuentran en una posición doble. Por un lado son portaestandartes de la construcción de conciencia

Revista Iberoamericana, Vol. LXXXI, Núm. 252, Julio-Septiembre 2015, 805-826 ISSN 0034-9631 (Impreso) 
a nivel local y, por el otro, buscan articular una conciencia unificada y universal que gira en torno a la experiencia compartida. Los tres tienen como común denominador la conjugación del quehacer literario con el avance de ideas políticas y en más de una ocasión integran la política en su literatura. ${ }^{6}$ Esta conjunción se debe especialmente a la importancia que tiene la política en su vínculo con los constituyentes en períodos de cambio y cimentación del ente nacional. Es claro que para la segunda mitad del siglo XIX el lazo con la corriente social es fundamental y se encarna más de una vez en el lenguaje poético de muchos de los escritores-intelectuales. La conexión se ve resumida, por ejemplo, en los Versos sencillos de José Martí cuando dice que "Yo vengo de todas partes, / y hacia todas partes voy: / Arte soy entre las artes, / En los montes, monte soy" (16). Sin embargo, el nexo sólo es viable para el intelectual hispanoamericano de entresiglos si fusiona dentro de su identidad representacional el nivel del discurso político y el nivel del discurso escritural, o en otras palabras, si logra compaginar el elemento práctico y directo de la experiencia local con la construcción de un discurso que promueva empatía y solidaridad al nivel supranacional.

Podría tildarse de optimista, si no de ingenua, la posibilidad de poner en práctica este papel intermedio del intelectual hispanoamericano como una especie de anfibio cultural, apto para traducir y transportar perspectivas entre diferentes medios, pero a la misma vez capaz de mantener una perspectiva siempre crítica e incómoda. Visto así, un intelectual no sólo debería producir ideas que subvierten el orden establecido sino que también debería intentar construir los puentes necesarios para hacerlas realidad. Como se ve, semejante objetivo se acerca mucho a un acto de prestidigitación, pero en el caso del fin del siglo XIX, se podría pensar en varias maneras en que un intelectual hubiera intentado establecer estos puentes -sin embargo, debe admitirse que no parece

6 Con la imbricación del elemento político estos tres autores refutan el precepto de George Orwell cuando asevera que "cuando un escritor se involucra en política debe hacerlo como ciudadano, como ser humano, pero no como escritor" (267; énfasis en el original). Al contrario de lo que dice Orwell, en Hispanoamérica, y aún más en el siglo XIX hispanoamericano, es la conjunción de las dos esferas, y no su separación, la que proyecta la identidad del intelectual y la que le posiciona en el papel de formador y conductor de valores culturales. El hiato propuesto por Orwell también es eliminado en la discusión sobre el intelectual propuesta más recientemente por autores como Said. Para Said, muy en el espíritu hispanoamericano decimonónico, el intelectual (artista, escritor, periodista) es alguien que orgánicamente interviene en política.

De manera paralela a la objeción de la idea de Orwell, el ejemplo de los intelectuales decimonónicos que he mencionado ataca la definición expuesta por Max Weber cuando afirma que los intelectuales son "un grupo de hombres quienes en virtud de su peculiaridad tienen acceso a ciertos logros considerados 'valores culturales', y quienes, en consecuencia, se apropian del liderazgo de una comunidad cultural" (176). Esta definición indicaría que los intelectuales son un grupo reducido o escogido, cuya actividad pareciera estar por fuera de la corriente social: productores de símbolos que viven a expensas de los símbolos. Sin embargo, como lo muestro con el ejemplo del precepto poético de José Martí, en Hispanoamérica decimonónica éste no es el caso.

Revista Iberoamericana, Vol. LXXXI, Núm. 252, Julio-Septiembre 2015, 805-826 ISSN 0034-9631 (Impreso) ISSN 2154-4794 (Electrónico) 
haber una fórmula que libere definitivamente al intelectual de la posible acusación de ser intelectual hispanoamericano incompleto, esto es, de no cumplir con su rol intermedio como anfibio cultural y al mismo tiempo como crítico incómodo. Una posibilidad era conectarse con un líder en el poder que estuviese dispuesto a escucharle, o ser parte del proceso por medio del cual un líder político, inmerso en las mismas ideas del intelectual, adquiriera el poder. Un ejemplo claro en este sentido es el de la relación entre Juan Montalvo y el líder liberal ecuatoriano Eloy Alfaro. Otra manera de conexión, ejemplificada por el cubano José Martí, es la participación activa en la construcción paciente y sostenida de una base popular altamente politizada, que en términos generales apoya la ideología liderada por el intelectual y que se moviliza para producir el cambio deseado. Sin embargo, parece que esta vía funciona claramente sólo en el caso de las revoluciones, como las muchas que hubo en Latinoamérica durante el XIX, y dejaría en suspenso la función del intelectual una vez conseguido, o logrado a medias casi siempre, el objetivo revolucionario.

Una tercera forma en que el intelectual decimonónico hispanoamericano podía negociar su posición intermedia era establecer conexiones con los detentadores del poder económico o con aquellos que posibilitaban la dispersión de idearios políticos. En esta clasificación se podrían incluir muchos escritores (Rubén Darío, Amado Nervo, Enrique Gómez Carrillo, Manuel Gutiérrez Nájera, José Martí o José Enrique Rodó, entre otros), pero el problema que confrontaríamos sería establecer quiénes de ellos deben ser considerados como intelectuales teniendo en cuenta la definición que incluye necesariamente el elemento político en oposición al elemento únicamente erudito o exclusivamente literario.

Vargas Vila no parece encajar en ninguna de las propuestas anteriores. Su defensa de la idea de individualidad radical parece haberlo puesto en una posición desequilibrada que buscaba el afecto del público para luego renegar de ese afecto. Vargas Vila se ubicó en el papel intermedio entre traductor y crítico de una manera fragmentaria que sólo logró unidad en el culto dramático o performativo de su persona. Los escritos de Vargas Vila consiguieron, como ningún otro intelectual colombiano ha podido hacerlo, establecer contacto directo y continuado con el pueblo raso, con los trabajadores, con los grupos que no tenían derechos legales, o privilegios, o inmunidades. El discurso literario o político del bogotano -no parece haber frontera entre los dos en su escritura- produjo efectos en esos grupos constituyentes saltando por encima de las elites que dirimían el quehacer cultural de la nación. Esta vigencia del pensamiento de Vargas Vila entre las clases populares es un hecho incontrovertible que se comprueba constantemente por la piratería de su obra, aún en nuestros días, lo que lleva a plantear la tesis de que lo que a primera vista parece ser una falencia narcisística y fosilizante de la producción de Vargas Vila se constituye de una extraña manera en el salto de la producción de ideas a su realización, no en el sentido literal de obras hechas o batallas ganadas, sino como constante presencia espectral. Vargas Vila parece haber logrado el mismo objetivo de

Revista Iberoamericana, Vol. LXXXI, Núm. 252, Julio-Septiembre 2015, 805-826 ISSN 0034-9631 (Impreso)

ISSN 2154-4794 (Electrónico) 
inmanencia cultural alcanzado por Martí. La diferencia es que con su muerte, y las muchas facciones políticas que lo han usado como portaestandarte, Martí alcanzó tal perdurabilidad como héroe, mientras que Vargas Vila, con su incomodidad incómoda, la habría obtenido como proscrito.

Por supuesto que la posición incómoda tomada por Vargas Vila es ambigua, por supuesto que su obra está llena de contradicciones internas, de aforismos impuestos sobre sus lectores pero no cumplidos por el autor; por supuesto que predica y a veces no aplica, que encubre y encumbra zonas de su experiencia vivida. Esta incomodidad dubitativa y falible, que fluctúa entre la glorificación y el insulto del ser hispanoamericano, no hace sino confirmar que el intelectual es un individuo cuyo centro vital es el constante ejercicio del disenso, aún si esa oposición es ejercida contra los que se acaba de defender. A esto algunos lo llaman cambiarse la chaqueta, pero desde un punto de vista orgánico es llanamente la función del intelectual. Este asunto de la lealtad-del intelectual en general pero de Vargas Vila en particular- hacia las ideas o gobiernos previamente defendidos y a lo mejor posteriormente atacados, es un punto serio que es necesario abordar, ojalá de la manera más desapasionada posible.

Algunos críticos polemizan sobre si, como intelectual político, Vargas Vila se mantuvo o no constante en sus adscripciones, o si se desvió o no de su camino como persona pública para obtener beneficios para su persona privada. Como pruebas de su constancia con respecto al ideario liberal radical decimonónico se pueden consignar su salida de Colombia para escapar del gobierno regenerador y su subsecuente deambular por Estados Unidos y Europa, una errancia que ni siquiera terminó con su muerte en Barcelona, lejos de su país, en 1933. A lo anterior se suma su temprana adhesión a la causa libertaria de Martí, su defensa del gobierno de Eloy Alfaro en Ecuador y su crítica sostenida contra los que vio como déspotas en Hispanoamérica. Como prueba de su desviación tendríamos que Vargas Vila habría recibido, o habría pedido, apoyo económico de diferentes gobernantes -sabemos que recibió cargos diplomáticos del gobierno ecuatoriano, que fue secretario del presidente venezolano Joaquín Crespo, y que recibió dinero del presidente mexicano Álvaro Obregón para continuar la publicación de su revista Némesis. También sabemos de sus múltiples jugadas editoriales, los cambios de títulos y reescrituras a medias de sus libros, que vendía y revendía buscando claramente la ganancia económica. El estudio detallado del corpus escritural de Vargas Vila sorprende, pues se observa recurrentemente la clara intención comercial -mayor cantidad de ganancia económica con el uso mínimo de recursos- que saca ventaja de la idea del espíritu combativo y justiciero del autor.

Una evaluación demasiado rápida, sin duda justificada hasta cierto punto, que ve al pensador público como alguien que pertenece a una especie de sacerdocio secular descartaría de un sólo plumazo a Vargas Vila de su condición de intelectual. Sin embargo, no se debe perder de vista que el intelectual es un individuo de su momento, a caballo entre el mundo privado y el mundo público. Como ya se ha mostrado, el intelectual

Revista Iberoamericana, Vol. LXXXI, Núm. 252, Julio-Septiembre 2015, 805-826 ISSN 0034-9631 (Impreso) ISSN 2154-4794 (Electrónico) 
en su función cultural se ve avocado a mantener una posición que incorpora el mundo de la praxis y el de la teoría. Si a lo anterior se suma el hecho que los arbitrios y las circunstancias de la vida de Vargas Vila lo llevaron a vivir de su escritura -él, que no pertenecía a ninguna de las familias ricas y de influencia de su país, que no fue beneficiado por una educación prolongada en el extranjero, que decidió no dedicarse al periodismo como medio de sustento- empieza a entenderse que no es tan clara esa disyuntiva entre las convicciones políticas públicas del bogotano y sus desviaciones individuales y personales para obtener el sustento. La misma tensión entre convicción y supervivencia se ve claramente en otros personajes hispanoamericanos del siglo XIX a quienes no dudamos en catalogar como intelectuales, pero que como él se vieron insertos en la creciente lógica del mercado editorial: Rubén Darío recibió dinero y una posición consular en Argentina de manos de "El Regenerador" colombiano Rafael Nuñez y escribió regularmente a cambio de un estipendio para el periódico La Nación de Buenos Aires -el periódico Fundado por Bartolomé Mitre, aquél que abogaba por el aniquilamiento de los indígenas en Argentina. José Martí escribió para el mismo periódico y varios otros a cambio de remuneración y hasta escribió por encargo, en uno de sus momentos de escasez económica, una novela bajo seudónimo femenino y con la intermediación en el negocio de una amiga que sirvió como frente para su publicación en un periódico para familias de la época. El ecuatoriano Juan Montalvo recibió, aunque con gran amargura, el mecenazgo de Eloy Alfaro y los préstamos monetarios de sus amigos. La característica común de estos cuatro intelectuales es que precisamente ninguno de ellos provenía de las elites tradicionales que comúnmente relacionamos con el ámbito intelectual hispanoamericano. En cuanto a su procedencia económica y social, estos cuatro escritores son opuestos a un José Asunción Silva en Colombia -quien aunque siempre estuvo endeudado, siempre también vivió la vida muelle que sus apellidos y posición social le permitieron, y quien por sus relaciones familiares y encumbrado nombre recibió ayuda económica del regenerador presidente y gramático Miguel Antonio Caro-, a un Eugenio Cambaceres en Argentina, heredero de fortuna, o a un Vicente Huidobro en Chile, de familia acomodada e influyente, para tener una imagen de aquellos que tenían los medios expeditos para lograr sus objetivos intelectuales.

En Vargas Vila, Montalvo, Darío o Martí nos encontramos con productores emergentes de pensamiento, cuyo poder de influencia, en paralelo con el instrumento de su sustento, se halla a un mismo tiempo en la radicalidad de sus ideas y en la capacidad para mantenerse en la corriente de influencia cultural. Tal negociación frente a la realidad es obviamente el resultado de una economía de mercado, claramente urbana, caracterizada por la fugacidad con la que se producen cambios y por la necesidad de actualizar el lenguaje para que responda a las veleidades de la moda. En este tipo de entorno el pensador público debe a un mismo tiempo confrontar y acoplarse a la presión para constituirse en proveedor de servicios y en crítico de su sociedad. En otras palabras, como sucede con otros tipos de comercio tal y como surgieron en ese momento, el intelectual está en

Revista Iberoamericana, Vol. LXXXI, Núm. 252, Julio-Septiembre 2015, 805-826 ISSN 0034-9631 (Impreso)

ISSN 2154-4794 (Electrónico) 
riesgo de convertirse simple y llanamente en productor y comerciante de novedades en el sentido expuesto por Walter Benjamin en Das Passagen-Werk (The Arcades Project) cuando indica que el arte entra al servicio del mercado y del mercader, y que el artista o intelectual se presenta en la arena comercial supuestamente como observador, pero verdaderamente para tratar de conseguir un comprador (3). Esto es precisamente lo que pasa con el cronista, quien desde su columna ejerce el oficio de productor de opinión pública, cuyas raíces profundas en el caso hispanoamericano se encuentran en el siglo XIX, precisamente en el momento en que Vargas Vila está en el apogeo de su producción. ${ }^{7}$

Entonces la respuesta parcial sería que sí, que aún con muchas o pocas incongruencias entre lo público y lo privado Vargas Vila es un intelectual hispanoamericano decimonónico representativo. No es necesariamente que este intelectual se venda, sino más bien, como ha ocurrido tantas veces y en muchos otros contextos para los intelectuales -pienso en los ejemplos clásicos del Inca Garcilaso de la Vega o en Sor Juana Inés de la Cruz-, que se ve en la obligación práctica de desarrollar movimientos estratégicos que le permitan pervivir y al mismo tiempo poder mantener canales abiertos para difundir su posición contingente. Esta es la experiencia que muestra una vez más la afinidad que hay entre Vargas Vila y Martí. El pensador cubano es en muchos sentidos el ejemplo quintaesencial del intelectual hispanoamericano, y a él acudo para delinear con un poco más de precisión el papel de Vargas Vila como intelectual colombiano y continental. Sólo se conserva el contenido de tres cartas escritas por Martí a Vargas Vila, todas ellas fechadas a pocos meses de su muerte en mayo de 1895. A pesar de lo limitado del corpus, la cualidad altamente penetrante y sugestiva de la escritura del cubano -especialmente en la más extensa de las cartas- provee al crítico con un grupo de rasgos que permiten definir las cualidades del intelectual hispanoamericano de entresiglos y su verificación directa en Vargas Vila. Para estudiar estos rasgos conviene reproducir en su totalidad el documento referido para luego establecer una aproximación estructurada que permita identificarlos. La otra ventaja de esta estrategia es que permite reproducir en su totalidad un texto que por lo general ha sido abordado sólo de manera fragmentaria:

\section{Señor José M. Vargas Vila}

Mi amigo generosísimo:

Mida, por lo callado, lo profundo de mi agradecimiento. ¿Por qué aguardé hasta hoy para escribírselo? Porque siempre, desde niño, fui encogido y brusco para decir las cosas de mi corazón. Porque de años atrás sólo estoy en pie por la esperanza de ser útil, y tengo como invencible horror -aunque nunca obré mal ni pensé mal-de cuanto me

Los estudios clásicos y seminales sobre la crónica hispanoamericana del XIX son los desarrollados por Aníbal González Pérez. Para una discusión profunda del tema ver sus libros La crónica modernista hispanoamericana y Journalism and the Development of Spanish American Narrative.

Revista Iberoamericana, Vol. LXXXI, Núm. 252, Julio-Septiembre 2015, 805-826 ISSN 0034-9631 (Impreso)

ISSN 2154-4794 (Electrónico) 
pone ante mi propio. Es tal vez como un eco de los primeros espantos que me causó el mundo. Me ha mimado, como me mima ahora usted; pero ¿qué me importa, si con un dolor solo puede exceder todas sus caricias, y basta para afearlo irremediablemente el conocimiento de la injusticia y pena que hay en él? Me quedó como una hosquedad de mis primeros choques con el interés y soberbia de la existencia. La convicción de mi utilidad relativa me tiene vivo; pero me amarga y exaspera la imposibilidad de ser verdaderamente útil, contra tantos obstáculos como opone a la verdad la vida. - Un pobre gamo acorralado;- eso soy yo: y huyo, de los que se acercan, como usted a mi corral con la mano llena de azúcar.

Yo le amo a usted la palabra rebelde y americana, como hoja de acero con puño hecho a cincel, con que cruza las espaldas sumisas o los labios mentirosos: yo le amo la hermandad con que se liga usted, en este siglo de construcción y de pelea, con los que compadecen y sirven al hombre, contra los que lo encapotan y oprimen: yo le amo la perspicacia y ternura con que miró usted, en la fuente de toda mi energía que es la piedad infatigable de mi corazón.

Al pintar los méritos que usted cree ver en mí, sólo pintó los suyos: no traduce bien sino quien es capaz de crear lo que traduce: no se suponen en los demás sino las virtudes que se llevan en sí. Déjeme que lo abrace, con la alta tristeza de los que se despiden antes de entrar en el combate y el placer profundo de hallar un alma soberana, piadosa, sincera, erguida, amiga. Mi honor más grande es haberle parecido útil y bueno.

De su artículo sobre mí no le puedo decir, sin embargo, mucho: no lo he podido leer sino una vez, y como por sobre ascuas. La que sí he leído más es esa justicia de usted a nuestro maestro Rojas Garrido, que con una mano echaba atrás la traílla venenosa de los tiempos viejos, y los acogotaba y les burlaba los dientes, y con la otra, en la lava de nuestra época y país, moldeó la república. Lo que de usted habrá de quedar, entre las cosas mayores que han salido ya del horno de su mente, es su juicio indignado y definitivo, sobre ese hombre de pompa y reflejo en quien se ve la nulidad de la inteligencia, siquiera sea tan expresiva y coloreada como la suya, cuando sirve de peldaño y disfraz a un alma vana y arrogante. No es la inteligencia, recibida y casual lo que da al hombre honor: sino el modo con que la usa y la salva. No hay más que un modo de perdurar: y es servir. Es rebelde el hombre por naturaleza y echará siempre abajo a cuantos crean que se le puedan poner por delante o por encima.

El gusto es ir en la columna de marcha, como usted y como yo, confundido con la pena, bregando y perdonando, llorando, rugiendo, levantando al caído, cayendo. Todo es gozo cuando se pelea por la luz del mundo.

Y ahora ¿me perdona mi silencio? Y me espera a almorzar con Zumeta y Alfonzo. Voy detrás de la carta.

$\mathrm{Su}$

JOSÉ MARTÍ

Marzo 14, 1894

Revista Iberoamericana, Vol. LXXXI, Núm. 252, Julio-Septiembre 2015, 805-826 
Muy en el estilo de Martí, la carta está escrita de manera que el autor se desdobla para hablar de sí mismo como si hablara de un ente ajeno o escindido. El desdoblamiento es aún más complejo toda vez que la descripción tiene la forma de una refracción especular. Al hablar de Vargas Vila el narrador en realidad habla de Martí y cuando habla de Martí también quiere hablar de Vargas Vila: "Al pintar los méritos que usted cree ver en mí, sólo pintó los suyos." La cualidad especular que unifica a los dos personajes está dada porque Martí reconoce que Vargas Vila ha logrado entender alguna clave interior de la personalidad del cubano, pero que no ha utilizado ese conocimiento para atacarle, sino para abrirse frente a él en condiciones de igualdad: "yo le amo la perspicacia y ternura con que miró usted, en la fuente de toda mi energía que es la piedad infatigable de mi corazón". La situación de correspondencia entre los dos personajes corrobora de inmediato la manera en que Martí se autodefine como pensador en y para el ámbito público - esto es, como intelectual-y cómo Vargas Vila es incluido en esa definición. El verbo repetido que define la conexión entre los dos personajes y su función pública es muy fuerte: amar. No se trata de simple admiración, simpatía o predilección, se trata de afinidad de espíritu y de acción o, para utilizar una palabra manida, de fraternidad en la lucha. En primer lugar, y como prueba de la tautología decimonónica entre escritura e intelectualidad, la idea del intelectual hispanoamericano -él lo llama "americano"-gira en torno al uso de la palabra. Para Martí, el intelectual hispanoamericano es rebelde por antonomasia, ataca con sus escritos a los que tienen la espalda doblada por la sumisión frente al statu quo, arremete contra los que se acomodan a la situación que oprime a los suyos porque callan o mienten para seguir derivando beneficio particular a pesar de saber del mal que sufre la colectividad.

El intelectual se pone de lado de los oprimidos y en contra de los opresores de su momento y de su lugar, haciendo y diciendo lo que se ha de hacer -en otras palabras, armonizando la construcción de ideas y su realización, tal como se señaló al principio de este ensayo. En la referencia al texto que Vargas Vila escribiera sobre el político colombiano José María Rojas Garrido, Martí ofrece más detalles sobre esta función doble entre hacer y decir para el intelectual hispanoamericano. Por un lado, el intelectual actúa como iconoclasta que arremete contra las ideas y prácticas del pasado. Para llevar a cabo esta tarea usa un discurso ácido, disolvente, y heterodoxo que pone en evidencia la incongruencia existente entre el rancio statu quo y la necesidad actual de cambio. Por otro lado, con gran sentido de lo que es urgente, el intelectual ofrece los lineamientos prácticos que considera necesarios para el cambio.

Para Martí el intelectual tiene el "alma soberana"-esto es, tiene un espíritu individual e independiente-y piadosa, una cualidad que en términos del pragmatismo contemporáneo Richard Rorty calificaría de contingente y solidaria. El intelectual también es útil, sincero y bueno. Todas estas características - bondad, sinceridad, piedad-normalmente se entienden bajo los parámetros de la visión cristiana, lo que las haría sinónimas de mansedumbre y condescendencia, pero aquítienen claramente la connotación agresiva de

Revista Iberoamericana, Vol. LXXXI, Núm. 252, Julio-Septiembre 2015, 805-826 ISSN 0034-9631 (Impreso) ISSN 2154-4794 (Electrónico) 
quien erguido defiende sus ideas. Esta reciedumbre iracunda sirve al intelectual definido por Martí de una manera muy importante para el caso hispanoamericano de ayer y de hoy: con su juicio tajante el intelectual señala al simulador, aquel que amparado en la cortina de humo de las ideas importadas, de la terminología abstrusa, y de las lecturas de viñeta se muestra como representante del conocimiento para derivar beneficio personal y egoísta. La diferencia entre el intelectual de Martí y el censurado intelectual de la simulación es que el primero pone su inteligencia al servicio de la causa que busca el cambio. Con su lenguaje profético y elevado, que es casi el de una religión laica, Martí sitúa al intelectual en una procesión que es al mismo tiempo marcha militar, acompañado y diferenciándose -caminando y rugiendo-a la vez del soldado y del ciudadano raso mientras que mantiene su constante voz de crítica y soledad.

Hay un cambio drástico entre la reflexión profunda e íntima de toda la carta y la manera coloquial en que en el último párrafo Martí invita a Vargas Vila a almorzar, ya que muestra la escisión entre vida pública y vida privada tan propia del intelectual hispanoamericano. El énfasis sentencioso que pone en evidencia el estilo personal hacia la comunidad, pero que en este caso demuestra la manera en que el pensador se desnuda de su armadura -algo que Martí sólo hacía bajo la protección del lenguaje poético-, se transforma en un lenguaje que pone los pies del intelectual en la tierra, haciendo énfasis nuevamente en su cualidad anfibia o traductiva.

La carta está fechada en Nueva York, la ciudad representativa del espíritu estadounidense. Fuente de atracción y repulsión a la que llegaban y de la que se iban los exiliados hispanoamericanos. Nueva York, y Estados Unidos en general, es un punto de toque en que aquellos podían ver las grandes transformaciones de un país que había sido colonia y que ahora empezaba a mostrar tendencias colonizadoras; centro del comercio y de la experimentación artística, en el que el mercantilismo se embellecía con los avances tecnológicos y el arte se enlodaba con la comercialización. Nueva York es una ciudad cosmopolita pero norteamericana en que Martí almorzaba con Vargas Vila, Zumeta y Alfonzo, el ámbito en el que él y ellos discutían sobre sus tiranos y sus tiranías; el lugar al que temían, pero en el que tenían puerto relativamente seguro para intentar poner en la práctica proyectos de liberación revolucionaria. Esta ubicuidad contradictoria de los Estados Unidos se constituye en un topos fundamental para el intelectual hispanoamericano. El país norteamericano adquiere-con mucha razón y por muchas razones, hay que decirlo- la cualidad simbólica que facilita ideas de oposición anejas a la labor del intelectual hispanoamericano tempranamente detectables en el chileno Francisco Bilbao (1823-1865), quien de manera característica inició su posición frente al país del norte primero como admirador y luego como escéptico (Graña 216). Esta oposición se ve luego de manera vacilante en el ya mencionado Juan Montalvo, quien en su "La dictadura perpetua" antecede en quince años la advertencia de Martí de que los latinoamericanos debían unirse en contra de la agenda expansionista inicialmente

Revista Iberoamericana, Vol. LXXXI, Núm. 252, Julio-Septiembre 2015, 805-826 ISSN 0034-9631 (Impreso) 
vislumbrada por John Quincy Adams, refinada por James Monroe ${ }^{8}$ ensayada durante la Conferencia Pan-Americana de 1889 por el gobierno de James A. Garfield, ${ }^{9}$ y radicalizada con la doctrina del garrote por Theodore Roosevelt.

Tanto Montalvo como Martí inauguran un discurso oposicional a los Estados Unidos que se ha mantenido en boga hasta nuestros días. Los textos de Martí y Montalvo acusan a los Estados Unidos de ser un país de doble estándar que por un lado se presenta como fuente de ideas de libertad y autodeterminación, pero que luego socava a los países que buscan su propia autonomía cuando no compaginan con sus objetivos comerciales. Para estos intelectuales decimonónicos los Estados Unidos es un país que simboliza un enemigo común para las jóvenes repúblicas, pero a la vez observan que esta fuente simbólica sirve para crear una imagen que produce solidaridad. Vargas Vila es un ejemplo claro de la línea de oposición a las políticas del gobierno estadounidense y del uso de la imagen de ese país como enemigo común. De entre estos intelectuales representativos Vargas Vila es de hecho el ejemplo más claro y más radical de antagonismo hacia el país del norte. La ya mencionada obra Ante los bárbaros continúa siendo un hito referencial muy importante en la articulación del pensamiento latinoamericano frente a la ambivalente presencia norteamericana. La vigencia de este discurso se debe a la manera directa, tajante y hasta tosca en que el panfletista identifica al enemigo percibido. En el caso de Vargas Vila, la conformación de un enemigo común -se debe recordar que el subtítulo de su libro es El yanqui; he ahi el enemigo- podría ser entendida como estrategia para edificar una identidad hispanoamericana artificialmente positiva frente a la identificación negativa del enemigo. Ésta es por lo menos la manera en que el crítico peruano César Graña ha caracterizado la posición de intelectuales como José Martí en su ensayo "La metafísica de la frustración cultural". Graña afirma que en este tipo de autores hay una "idealización de Hispanoamérica, no como reina de la naturaleza o como hogar de la benevolencia social, sino como una especie de manifestación cultural particularmente

8 El presidente estadounidense James Monroe hizo públicas sus ideas de bloquear la influencia comercial de los países europeos en su mensaje al congreso de ese país en 1823. Por otro lado, Nicaragua había visto el beneplácito del gobierno de los Estados Unidos frente a las acciones del aventurero norteamericano William Walker, quien en 1856 se había hecho presidente de la república centroamericana y que terminaría siendo fusilado cuatro años después.

9 A este respecto, en diciembre 19 de 1889 (aunque el artículo está fechado en noviembre 2 del mismo año) Martí publica en La Nación de Buenos Aires un escrito que muestra de manera intelectualmente rebelde una definición oposicional para Hispanoamérica: "Jamás hubo en América, de la independencia acá, asunto que requiera más sensatez, ni obligue a más vigilancia, ni pida examen más claro y minucioso, que el convite que los Estados Unidos potentes, repletos de productos invendibles: y determinados a extender sus dominios en América, hacen a las Naciones americanas de menos poder, ligadas por el comercio libre y útil con los pueblos europeos, para ajustar una liga contra Europa, y cerrar tratos con el resto del mundo. De la tiranía de España supo salvarse la América española; y ahora, después de ver con ojos judiciales los antecedentes, causas y factores del convite, urge decir, porque es la verdad, que ha llegado para la América española la hora de declarar su segunda independencia” (Obras completas Vol. 6, 46).

Revista Iberoamericana, Vol. LXXXI, Núm. 252, Julio-Septiembre 2015, 805-826 ISSN 0034-9631 (Impreso)

ISSN 2154-4794 (Electrónico) 
triunfante, con motivos indios, antiguos y cristianos" (219). Vargas Vila pertenece a esta clasificación sólo parcialmente. Es posible que él defienda la idea de Hispanoamérica como espacio en el que se verificó la subversión de un sistema opresivo y presuntuoso como el de la metrópoli española y que en ese sentido se podría reclamar una identidad triunfante. Sin embargo, es claro que esta idea aglutinadora inicial está drásticamente morigerada por su visión escéptica del destino de Hispanoamérica tras los regímenes dictatoriales posteriores a la independencia que él mismo fustigó.

Vargas Vila se acerca más bien a la calificación peyorativa que hace Graña al afirmar que "[1]a ontología cultural hispanoamericana es la metafísica de la frustración cultural" (243). Esta afirmación llevaría entonces a definir al intelectual hispanoamericano como un individuo que además de estar frustrado busca, entre otras cosas expresar, estudiar, entender semejante frustración. Es claro que Graña quiere utilizar un tono irónico y hasta ofensivo al decir que la frustración es la marca ontológica hispanoamericana. Pero vista esa marca con seriedad, podría encontrarse en ella mucho de cierto. Primero habría que precisar qué entenderíamos por frustración; esa supuesta mácula podría entenderse como un punto de partida, como una fuerza catalizadora de búsquedas nuevas. Lejos de la ironía y el derrotismo con ínfulas de superioridad de Graña, la marca de la frustración incorpora necesariamente la idea de dinamismo, porque sólo es frustrante no encontrar el resultado de lo que se ha buscado activamente. A nadie le gusta que lo llamen frustrado, pero luego de revisar qué significa ser intelectual desde el siglo XIX, en el mundo occidental y en la particularidad hispanoamericana, se puede entender a Vargas Vila precisamente como un intelectual que abiertamente entendió la frustración cultural hispanoamericana como su marca ontológica y como su marca personal. Aceptar semejante condición produce duda. Pero del mismo modo que la afirmación de Gutiérrez Girardot que comenté al inicio de este ensayo sobre el papel de Vargas Vila como intelectual era en realidad una pregunta dubitativa, la respuesta sobre la intelectualidad hispanoamericana, o la de Vargas Vila, realmente no está en ninguno de aquellos a quienes podamos considerar como intelectuales: se encuentra más bien en nuestra reacción informada frente a lo que ellos dijeron. 


\section{OBRAS CITADAS}

Benjamin, Walter. The Arcades Project. Howard Eiland y Kevin McLaughlin, trad. Cambridge: Harvard UP, 2003.

González Espitia, Juan Carlos. On the Dark Side of the Archive: Nation and Literature in Spanish America at the Turn of the Century. Lewisburg: Bucknell UP, 2010.

González, Aníbal. Journalism and the Development of Spanish American Narrative. Cambridge: Cambridge UP, 1993.

La crónica modernista hispanoamericana. Madrid: Ediciones José Porrúa Turanzas, 1983.

Graña, Cesar. "La metafísica de la frustración cultural". Los intelectuales políticos. Juan F. Marsal, intro. y sel. Buenos Aires: Ediciones Nueva Visión, 1971.

Johnston, William M. “The Origin of the Term 'Intellectuals' in French Novels and Essays of the 1890s." Journal of European Studies 4/1-13 (1974): 43-56.

Joyce, James. A Portrait of the Artist as a Young Man: Authoritative Text, Backgrounds and Contexts, Criticism. John Paul Riquelme y Hans Walter Gabler, eds. New York: W.W. Norton, 2007.

Retrato del artista adolescente. Dámaso Alonso, trad. Madrid: Alianza Editorial, 2002.

Maclean, Ian, Alan Montefiore y Peter Winch, eds. The Political Responsibility of Intellectuals. Nueva York: Cambridge UP, 1990.

Martí, José. Obras completas 16-17. 28 vols. La Habana: Editorial Nacional de Cuba, 1963-1973.

Molnar, Thomas Steven. The Decline of the Intellectual. Cleveland: Meridian Books, 1961.

Montalvo, Juan. "La dictadura perpetua". Las catilinarias; El cosmopolita; El regenerador. Caracas: Biblioteca Ayacucho, 1977.

Montefiore, Alan. "The Political Responsibility of Intellectuals." The Political Responsibility of Intellectuals. Ian Maclean, Alan Montefiore y Peter Winch, eds. Nueva York: Cambridge UP, 1990. 201-228.

Orwell, George. "Writers and Leviathan." The Intellectuals: A Controversial Portrait. Georg B. de Huszar, ed. Londres: Allen \& Unwin, 1960.

Rorty, Richard. Contingency, Irony, and Solidarity. Cambridge: Cambridge UP, 1989. Said, Edward W. Representations of the Intellectual: The 1993 Reith Lectures. London: Vintage, 1994.

Representaciones del intelectual. Isidro Arias, trad. Barcelona: Paidós, 1996.

Sartre, Jean-Paul. Plaidoyer pour les intellectuels. Paris: Gallimard, 1972.

Szacki, Jerzy. "Intellectuals between Politics and Culture." The Political Responsibility of Intellectuals. Ian Maclean, Alan Montefiori y Peter Winch, eds. Nueva York: Cambridge UP, 1990. 229-246.

Revista Iberoamericana, Vol. LXXXI, Núm. 252, Julio-Septiembre 2015, 805-826 
Vargas Vila, José María. Ante los bárbaros. Barcelona: Ramón Palacio Viso, 1930. Belona Dea Urbis. Barcelona: Casa Editorial Maucci, [1910?].

Weber, Max. From Max Weber: Essays in Sociology. H. H. Gerth y C. Wright Mills, ed. y trad. Londres: Routledge \& Kegan Paul, 1961. 